\title{
Comprehensive Modulation and Classification of Faults and Analysis Their Effect in DC Side of Photovoltaic System
}

\author{
Mehrdad Davarifar, Abdelhamid Rabhi, Ahmed El Hajjaji \\ University of Picardie “Jules Verne”, Laboratory MIS (Modeling, Information \& Systems), \\ 33Rue Saint Leu, Amiens, 80039, France \\ Email: Davarifar@ieee.org
}

Received April, 2013

\begin{abstract}
The first step in automatic supervision, condition monitoring and fault detection of photovoltaic system is recognition, exploration and classification of all possible faults that maybe happen in the system. This paper aims to perceive, classified, simulate and discus all electrical faults in DC side of photovoltaic system, regarding electrical voltage and current inspections. For that, simplified hybrid model of photovoltaic panel in MATLAB environment is used. Investigation and classification of each type of faults is down and the effects of the faults are illustrated in this paper. Flash test are applied to improved electrical model. Current-Voltage curves signature are interpreted and investigated in simulation environment.
\end{abstract}

Keywords: Photovoltaic Systems; Modeling; Electrical Fault; Fault Detection

\section{Introduction}

Nowadays photovoltaic (PV) panels are used in several sector of industry. They could be found, on building roofs, illuminated highway signs [1], etc. where rural electrification is embryonic [2], even in infrastructure industries such as oil industry [3], huge power plant in desert and different aspects of life. PV markets are growing fast because of their advantages such as: pollution free, safety, noiseless, easy installation, and short construction period. Also tariff of the solar electricity is enormous compared to the traditional power especially in peak load time [4]. Enquiries for lower cost and highefficiency-devices motivate the researchers to increase the reliability of PV systems.

On the other hand, this wide diffusion has of the distributed generation (DG) such as photovoltaic panels have not been supported by monitoring, fault detection and diagnosis equipment.

In fact, monitoring systems represent an additional cost and it weighs appreciably on Residential Photovoltaic System (RPS). For this reason, small PV plants are not regularly checked and partial system faults can occur, leading to energy losses that are dificult to be observed and causingfinancial losses [5-7]. Without proper fault detection, non-cleared faults in PV arrays not only cause power losses, but also might lead to safety issues and fire hazards [8].
Photovoltaic system are subjected to different sort of failures, thus before starting supervisory system and fault diagnosis methods, it is necessary to identify what kind of failures can be found in the real system. The first step in this challenge is to cognition and classification all possible faults, in the first.

On the other hand, the fault detection methods for the PV array are varied and are classified in the Table 1. Among these methods such as: visual, thermal, and electrical, the visual and the thermal methods need to look down the PV array and observe the color changes of the modules or observe the thermal properties such as hot spots. These methods need thermal cameras or other equipment in front of the array, while the electrical methods need only the output terminal of the array to measure the voltage, current, and signal data such as temperature and irradiation.

This characteristic of electrical methods is important for the fault diagnosis technologies to install them into the power conditioners or into the system inspection equipment. Then, electrical methods are promising for PV system fault diagnosis [10, 11]. This paper aims to perceive, simulate and discuss about electrical fault in DC side of photovoltaic system and has been focused on electrical voltage and current inspections. For that simplified hybrid model of PV panel in MATLAB environment is proposed in third part [12-15]. 
Flash test is spanning of the I-V curve ranges from the short circuit current $\left(I_{s c}\right)$ at zero volts, to zero current at the open circuit voltage $\left(V_{o c}\right)$. The measured and predicted curve shapes may disagree to some extent even when the PV string (or module) under test is performing perfectly. This could be caused by errors in irradiance or temperature measurement, or effect of the fault that has been classified in section two.

\section{Classification of Faults in DC Side of PV System Based on Location and Structures}

Generally speaking, faults in PV system could be occurred into two side of the system: DC side and AC side, the interface between this to part is DC/AC inverter that connected to grid. Internal maximums point power tracker algorithm with some method must be applied for rising efficiency of the system.

In AC side of PV system, typically two types of faults could be happened: total black out which considered as exterior fault for system, lighting and unbalanced voltage or grid outage for AC part defect such as switch frailer, over current or over voltage and etc. This sort of defect is not investigated in this work. Besides, it is considered that the PV array is the only source of fault, since most PV inverters contain transformers that could provide good galvanic isolation between PV arrays and utility grids and perfect electrical protections.

\subsection{Typical Faults in PV Array}

Typical faults in PV arrays consist of two main groups, PV panel fault and cabling. In large scale system, some method of cabal testing could be applied such as earth capacitance measurement (ECM) and the time-domain reflect (TDR) [16], but for small PV and domestic application these equipment test are so costly. In addition, number of PV and length of transfer power line in residential photovoltaic system is finite, and then in this study has been just focused on integrated panel.

Four of the most common types of fault in PV system (Earth Fault, Bridge Fault, Open Circuit Fault and Mismatch Fault) are described and simulated.

\subsubsection{PV panel/Module Faults}

\section{1) Earth Fault}

Earth fault is the most common fault in PV and occurs when the circuit develops an unintentional path to ground. According to NEC Article 690.5, two types of grounding shall be provided for PV system. The first one is system grounding: (the negative conductor usually is grounded via the Earth fault protection device (GFPD) in the PV inverter (Figure 1). The other one is the equipment grounding: the exposed non-current-carrying metal parts of PV module frames, electrical equipment, and conduc- tor enclosures should be grounded.

Two types of Earth faults with zero impedance at different locations have been studied and their fault currents are predicted in simulation

a) Lower Earth fault: the potential fault point is upper than half of the maximum voltage power point.

b) Upper Earth fault: This fault will cause large backed current and very high Earth-fault current. This case of faults is easily detectable by a change of the sign of the monitored primary current of the solar inverter. An additional sensor is not necessary. If the primary current becomes negative, some modern solar inverters initiate a controlled internal short circuit [17].

2) Bridging One or More Panels:

A fault bridging in PV system is happened when lowresistance connection established between two points of different potential in string of module or cabling. Bridging faults in PV arrays may be caused by insulation failure of cables such as an animal chewing through cable insulation, mechanical damage, water ingress or corrosion.

3) Open Circuit Fault:

When one of the current-carrying paths in series with the load is unintentionally broken or opened, an open circuit fault can be created. Some examples of this are poor connections between cells, plugging and unplugging connectors at junction boxes, or breaks in wires. In general, a series arc fault has less energy than a parallel bridging fault, but it has a much higher probability of occurring due to the large number of connections in PV systems.

4) Mismatch Fault:

Mismatches in PV modules occur when the electrical parameters of one or group of cell are significantly changed from other. In addition, mismatch faults are caused by interconnection of solar cells or modules, which experience different environmental conditions (i.e. irradiance or temperature) from one another. Mismatch faults are the most common type of fault compared with

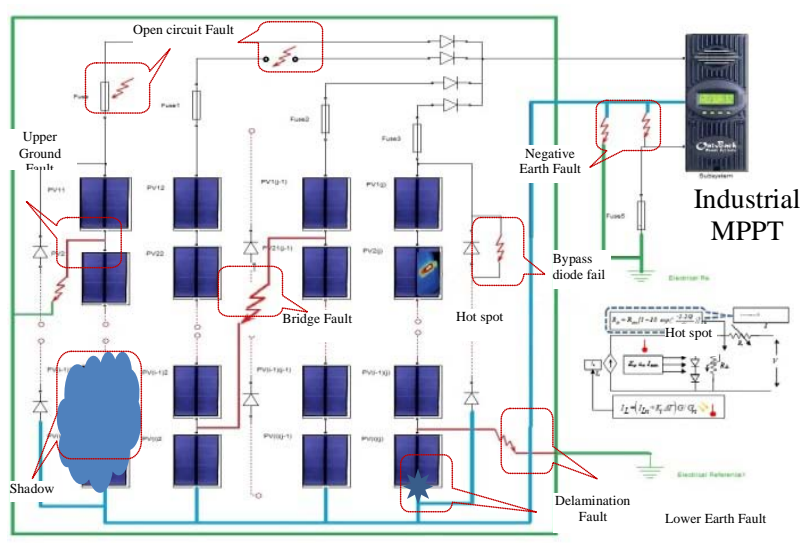

Figure 1. Fault schematic in DC side of PV system. 
Earth fault and bridging faults, among PV arrays. Mismatch faults may lead to irreversible damage on PV modules and large power loss. However, they are difficult to detect using conventional protection devices, since they generally do not lead to large fault currents.

These faults can be categorized into two groups, permanent and temporary. Their causes are listed below:

a) Temporary Mismatches: are divided in two groups:

- Partial shading:

Shading effect occurs when a part of the panels array are shaded which can be caused by a number of different reasons, like shade from the building itself, light posts, chimneys, trees, clouds, dirt, snow and other lightblocking obstacles [18].

Non- uniform temperature: Snow covering,

b) Permanent Mismatches:

\section{- Hotspot:}

Hot spot heating occurs when a module's operating current exceeds the reduced short circuit current of a shadowed or faulty cell or group of cells within the module [19]. To create a Hot spot fault, a variable resistor in series with the $R_{s n}$ of each defective cell could be added in Simulink. Value of this resistor is considered approximately one until five ohm.
- Soldering: this defective appears in resistive solder bond between cell and contacted ribbons.

- between cells and contact ribbons, Degradation:

$$
\begin{array}{ll}
\text { o } & \text { Discoloration; } \\
\text { o } & \text { Delamination; } \\
\text { o } & \text { Transparent layer crack. }
\end{array}
$$

Typical Chart of fault in (Figure 2) is illustrated:

\subsubsection{Cabling Fault}

Such as PV panel three principal type of fault is occur in power line carrier and cabling system.

1) Bridging Fault:

A very typical location of a possible bridging fault could be an aged connection box at the back side of a solar panel or in the corner and bend aria of cable [20].

2) Open-Circuit fault;

3) Earth Fault:

a) Upper Earth Fault

b) Lower Earth Fault

These common faults occur between panels and ground. Earth fault results in lowered output voltage and power, and can be fatal if the leakage currents are running through a person. These faults have almost the same effect on PV array and PV panel.

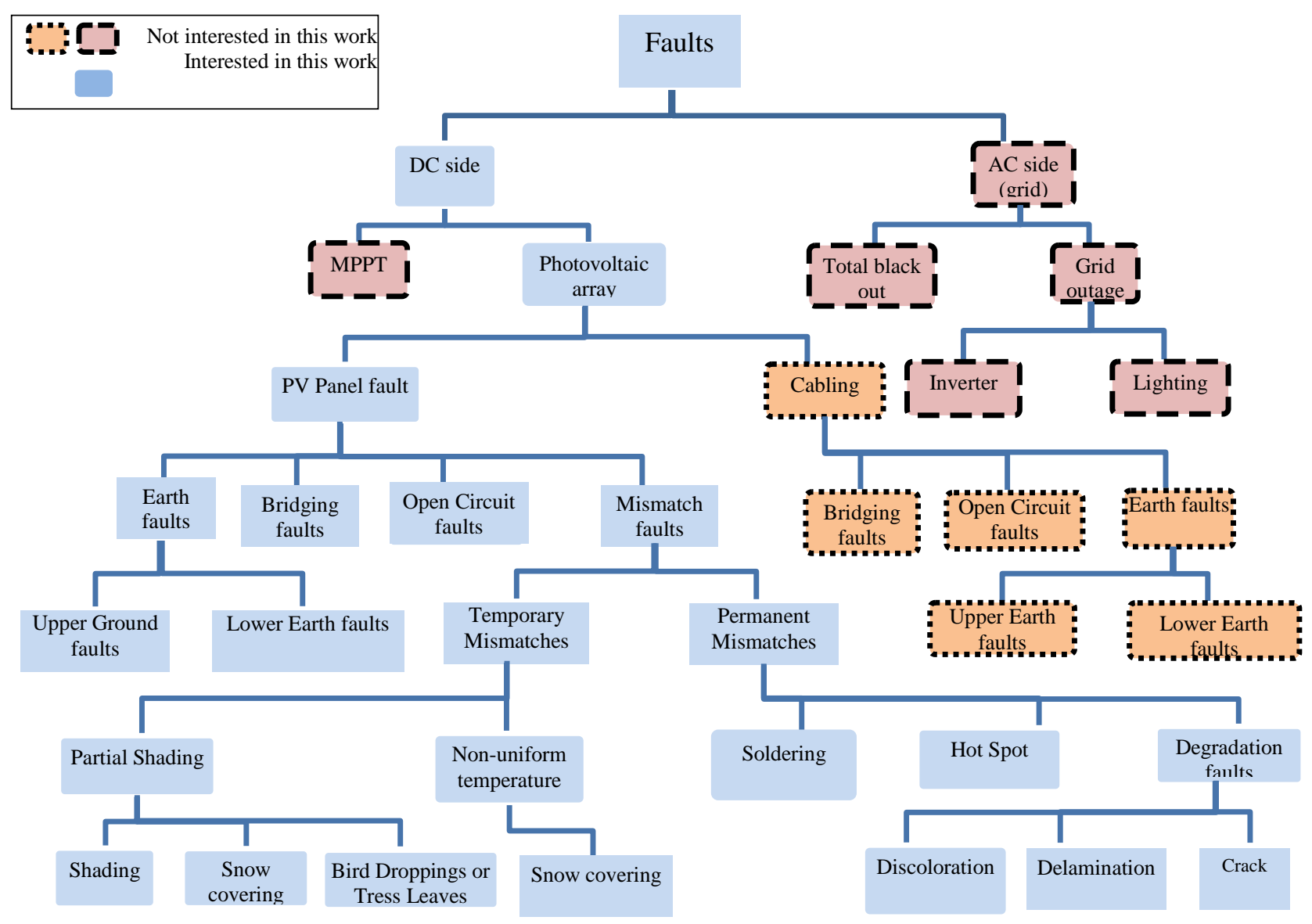

Figure 2. Classification of Faults in DC Side of PV system based on location and structures. 


\section{Simulation and Experimental Results}

\subsection{MATLAB/Pspice Circuit Based Model of PV Panels for Fault Diagnosis Application}

Photovoltaic system are subject to different sort of failures. Therefore, before stating health monitoring and fault diagnosis in PV system, finding general and real time model of PV, with good and fast performance is inevitable. This general and universal model must have following specification:

- $\quad$ Applicable for almost all commercial PV panel;

- $\quad$ Capable to work in real-time for fault diagnostic deliberation and monitoring system;

- Capable to simulate partial shading conditions (PSC) effect and degradation to investigate panels fault;

- Possible to connect easily and interfaced to the electronic devices and power converters model in MATLAB Simulink for maximum power point tracking and fault diagnosis studies.

Hybrid model is used and adopted according to the PV datasheet value for better $I-V$ curve estimation. In fact, equivalent circuit of a practical PV device includes the cells connected in series and parallel.

With this modification it is possible to change input data (irradiating and temperature) for each cell and simulate it individually. Of complying with superposition rules the simulation result of each cell combine together to form $I$ - $V$ characteristic of PV module as the output.

In our model (Figure 3):

- $\quad$ Dependent current source to irradiation and temperature for each cell are considered separately, in order to convert solar energy to electrical form;

- $\quad$ Adopted diode has been superseded instead of normal silicon diode;

- Variable resistor is used to appearance effect of solar irradiation (especially for Amorphous technology);

- $\quad$ Adopted diode connected in series form to demonstrate number of $\mathrm{P}-\mathrm{N}$ junction and became justification for high-level ideality factors $a$.

Using Spice diode block, it is possible to consider environment temperature effect in the simulation. In fact, the diode saturation current $I_{\text {sat }}$ and band-gap energy $E_{g}$ is corrected regarding datasheet value, and then parameters are manipulated in diode block. This procedure could be extended for PV arrays, output of each PV panel/module connected together according array configuration to form total $I-V$ curve.

\subsection{Simulation of Fault in Real Time}

The model presented in this work is implemented and tested on the a-Si:H triple layer amorphous. The panels are installed in MIS laboratory energy renewable plat- form in university of Picardie Jules Verne (Fiugre 4). Solar irradiation data is captured by pyrometer CS300. This pyrometer connects directly to our data loggers.

$\mathrm{PV}$ temperature is sensed with a type $\mathrm{K}$ thermocouple (Silicone rubber patch with self-adhesive aluminum foil backing) that mounted on panels, also RMS value of voltage and current are captured by national instrument data acquisition device (NI DAQ 6212 USB).

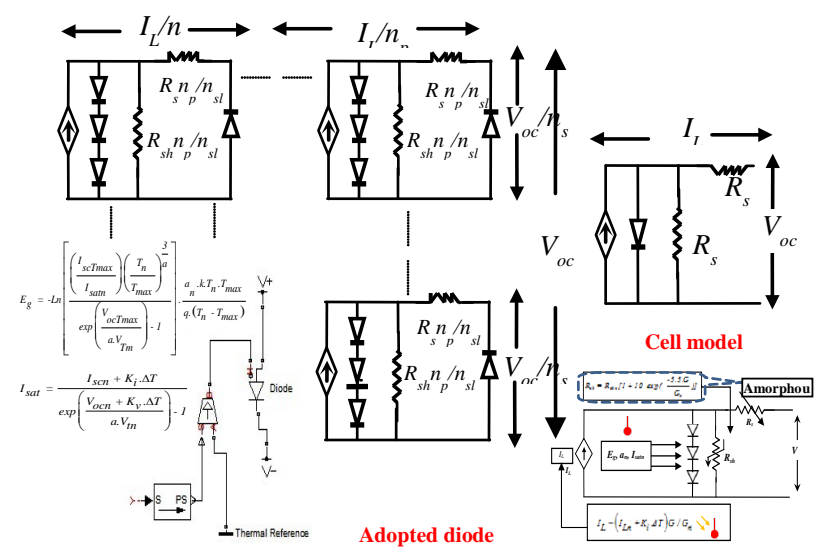

Figure 3. MATLAB/Pspice circuit based model of PV panels for fault diagnosis application.

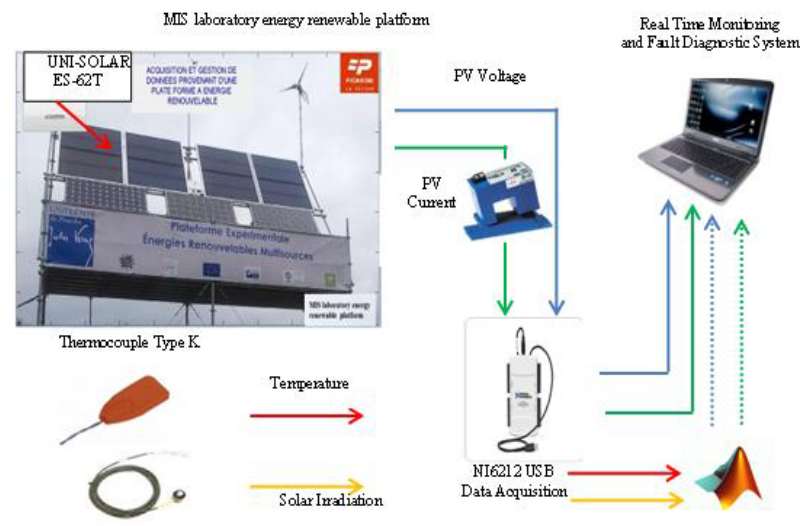

Figure 4. Evaluated Simulink model in MIS laboratory Energy renewable platform.

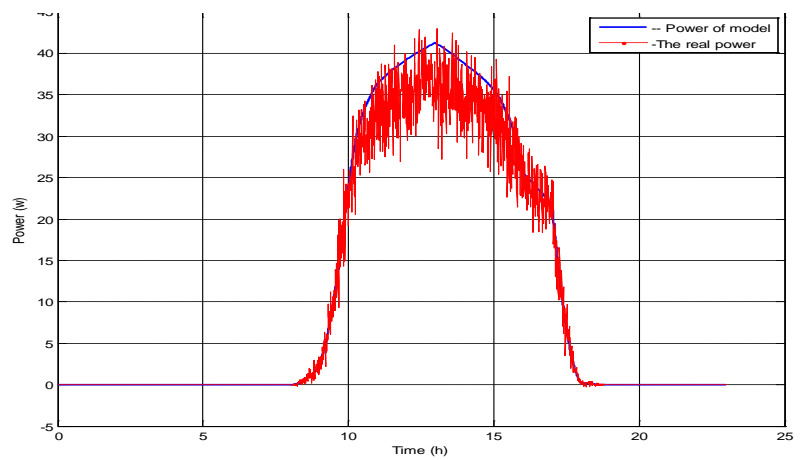

Figure 5. Comparison between the actual and the power provided by the model. 
Temperature and irradiation captured as input data. The voltage and current predicted by simulation in real time. According to this figure, it appeared that there was a good agreement between the real data given by measurement sensors and the results obtained by simulation. This Comparison is fundamental task to Feasibility of error by considering power lowering.

\section{Flash Test Result of Faults in DC Side of PV System (I-V Characteristic)}

Flash test is a fundamental method for measuring the performance $I-V$ characteristics of photovoltaic panels by spanning the PV voltage from zero to open circuit in short time. The output of measuring is a set of data, which are determined by output peak power, open circuit voltage, short circuit current, operating voltage, current, or power and efficiency [21].

Flash test has been applied to PV models for different type of fault scenario. Results of fore principal of fault, Open circuit (Figure 6), Mismatched fault (Figure 7), Bridging Fault (Figure 8) and Erath Fault (Figure 9) are illustrated.

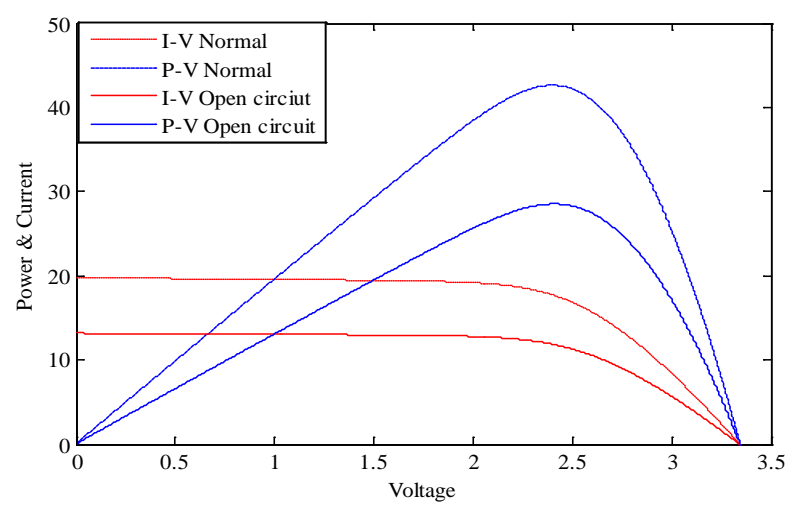

Figure 6. Open circuit fault affected on $I_{S C}$.

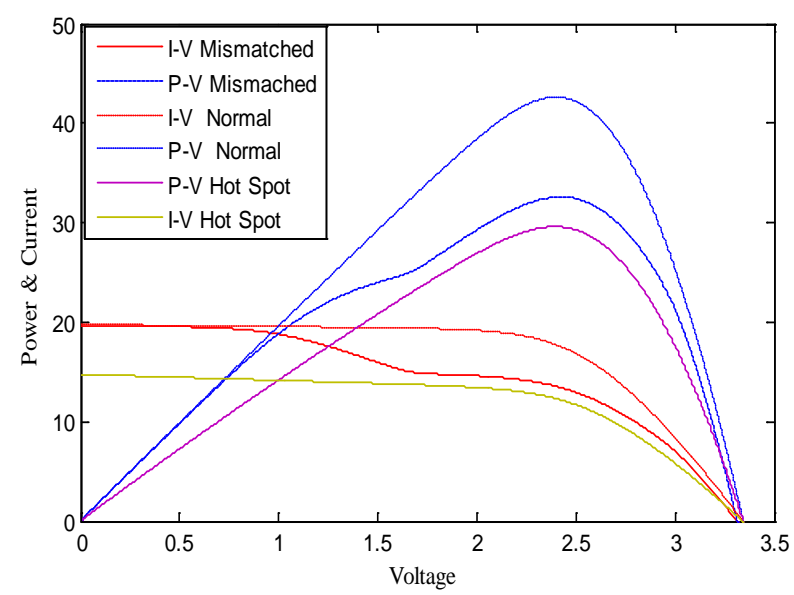

Figure 1. I-V curve has notches or steps in Mismatched and Hot spot fault.

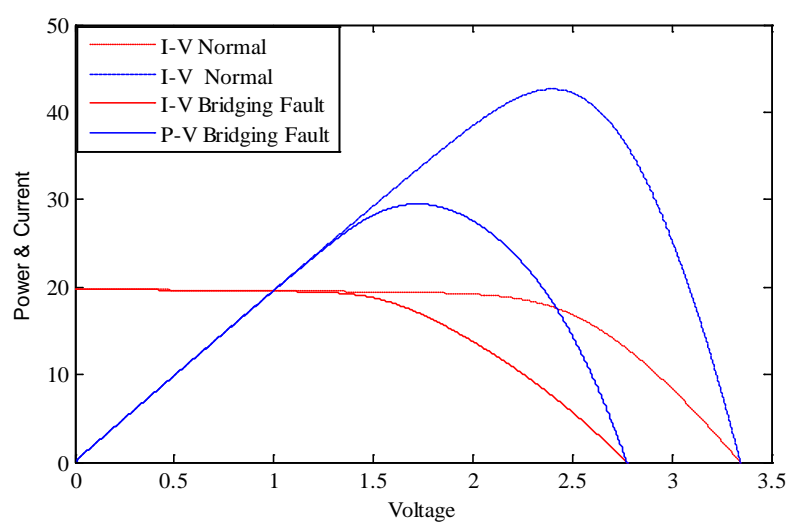

Figure 2. Bridging Fault Loses power and is effected on $V_{o c}$.

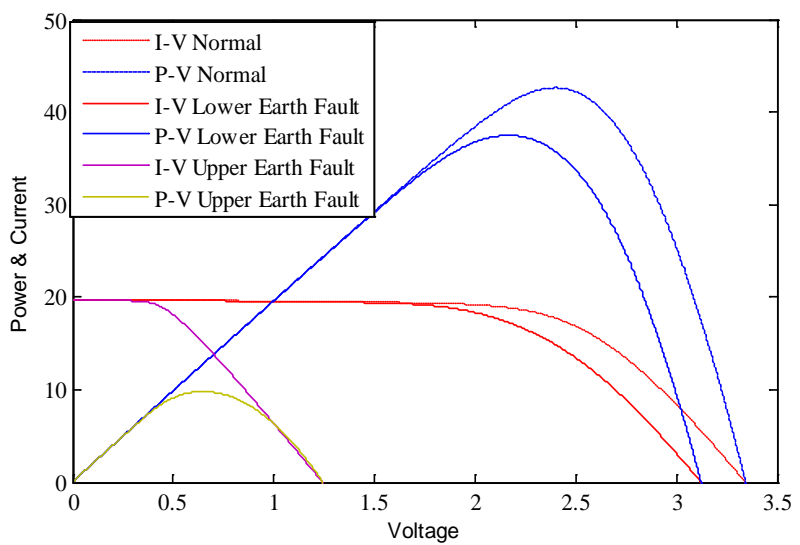

Figure 3. Earth Fault affected $V_{o c}$, Upper Earth fault is more effective in out-put characteristic.

For simulation initialize three strings in parallel and each string is included five cells or panel. (It is mentioned before that it is possible to consider PV module instead of cell, because the result is consequence of superposition rules).

Inference and investigated $I-V$ and $P-V$ Curve are interpreted at the end part of this study:

- The $I-V$ curve shows higher or lower current than predicted, which is caused by following faults:

- PV array is soiled (especially uniformly).

- PV modules are degraded.

- The slope of the $I-V$ curve near $I_{s c}$ does not match the prediction, if:

- Shunt paths exist in PV cells (Hot Spot)

- Shunt paths exist in the PV cell interconnects

- Module $I_{s c}$ mismatch

- The slope of the $I-V$ curve near $V_{o c}$ does not match the prediction, in cases below:

- PV wiring has excess resistance or is insufficiently sized

- Electrical interconnections in the array are resistive

- Series resistance of PV modules has increased

- The $I-V$ curve has notches or steps, if: 
- Array is partially shaded

- PV cells are damaged

- Bypass diode is short-circuited

- The $I-V$ curve has a higher or lower $V_{o c}$ value than predicted in the following cases:

- PV cell temperature is different than the modeled temperature

- One or more cells or modules are completely shaded

- One or more bypass diodes is conducting or shorted

- One or more PV modules were not included in the circuit as-built

\section{Conclusions}

A comprehensive classification of faults in DC Side of PV system based on location and structures is proposed for the first time. Flash test applied to validated model and deferent type of faults are simulated. Inference and investigated $I-V$ and $P-V$ curves are interpreted.

The future research plans to address some intelligent algorithm, which is used for fault detection and localization in PV system regarding the inference of $I-V$ and $\mathrm{P}-\mathrm{V}$ curves characteristics.

\section{REFERENCES}

[1] C. J. Huang, L. Y. Kang, Y. C. Jen, and C. S. Jen, “Design and Implementation of a Photovoltaic High-Intensity-Discharge Street Lighting System,” Power Electronics, IEEE Transactions, Vol. 26, No. 12, 2011, pp. 3464-3471. doi:10.1109/TPEL.2011.2116806

[2] M. Kolhe, "Techno-Economic Optimum Sizing of a Stand-Alone Solar Photovoltaic System," Energy Conversion, IEEE Transactions on, Vol. 24, No. 2, 2009, pp. 511-519. doi:10.1109/TEC.2008.2001455

[3] N. Groom, “Analysis: Oil companies go solar to tap hard-to-get supplies,” Ed: USA Edition; Reuters, 2011.

[4] D. Solyali and M. A. Redfern, "Why Should Cyprus Exploit the Solar Power to Match its Peak Demand?” Universities' Power Engineering Conference (UPEC), Proceedings of 2011 46th International, 2011, pp. 1-6.

[5] P. Ducange, M. Fazzolari, B. Lazzerini and F. Marcelloni, "An Intelligent System for Detecting Faults in Photovoltaic Fields," In Intelligent Systems Design and Applications (ISDA), 2011 11th International Conference on, 2011, pp. 1341-1346.

[6] S. Shojaee, M. Davarifar, M. H. Varahram and A. Davari, "Implementation of Remote Meter Reading Via Power Line,” In RCEE 2006,Gonabad Azad University, Iran, 2006.

[7] M. Davarifar, Z. Daneshi-Far and H. Fayyaz, "Implementation of Automate Remote Meter Reading (AMR) via BPL in Kish Island,” In International Power System Conference (PSC), 2009, Tehran, Iran., 2009.

[8] Y. Zhao, B. Lehman, J. F. DePalma, J. Mosesian and R. Lyons, "Fault Evolution in Photovoltaic Array during night-to-day Transition," In Control and Modeling for Power Electronics (COMPEL), 2010 IEEE 12th Workshop on, 2010, pp. 1-6.

[9] T. Takashima, J. Yamaguchi and M. Ishida, “Disconnection Detection using Earth Capacitance Measurement in Photovoltaic Module String," Progress in Photovoltaics: Research and Applications, Vol. 16, No. 8, 2008, pp. 669-677. doi:10.1002/pip.860

[10] S. Buddha, H. Braun, V. Krishnan, C. Tepedelenlioglu, A. Spanias, T. Yeider, et al., "Signal processing for photovoltaic applications," in Emerging Signal Processing Applications (ESPA), 2012 IEEE International Conference on, 2012, pp. 115-118.

[11] Z. Ye, Y. Ling, B. Lehman, J. de Palma, J. Mosesian and R. Lyons, "Decision tree-based fault detection and classification in solar photovoltaic arrays," in Applied Power Electronics Conference and Exposition (APEC), 2012 Twenty-Seventh Annual IEEE, 2012, pp. 93-99.

[12] M. Davarifar, A. Rabhi and A.Hajjaji, "Circuit Model Of PEM Fuel Cell For Energy Conversion Uses Renewable Energy System In Matlab," in The International Renewable Energy Congress (IREC), Hammamet, Tunisia, December 2011.

[13] M. Davarifar, A. Rabhi and A. E. Hajjaji, "Modeling of Solar Photovoltaic Panels in Matlab/Simscape Environment," in International Conference on Renewable Energy: Generation and Applications" ICREGA'12, Al Ain, United Arab Emirates, March 2012.

[14] M. Davarifar, A. Rabhi, A. E. Hajjaji and J. Bosche, "Real Time Modeling of Triple layers Amorphous Photovoltaic Panels," in 2d International Conference on Systems and Control (ICSC12),Marrakesh, Morocco , April 2012.

[15] M. Davarifar, A. Rabhi, A. Hajjaji, J. Bosche and X. Pierre, "Improved Real Time Amorphous PV Model for Fault Diagnostic Usage," in Sustainability in Energy and Buildings, Vol. 22, A. Hakansson, M. Höjer, R. J. Howlett, and L. C. Jain, Eds., ed: Springer Berlin Heidelberg, 2013, pp. 179-188.

[16] T. Takashima, J. Yamaguchi, K. Otani, T. Oozeki, K. Kato, and M. Ishida, "Experimental studies of fault location in PV module strings," Solar Energy Materials and Solar Cells, Vol. 93, No. 6-7, 2009, pp. 1079-1082. doi:org/10.1016/j.solmat.2008.11.060

[17] C. Strobl and P. Meckler, "Arc Faults in Photovoltaic Systems," in Electrical Contacts (HOLM), 2010 Proceedings of the 56th IEEE Holm Conference on, 2010, pp. 1-7.

[18] F. Ancuta and C. Cepisca, "Fault analysis possibilities for PV panels," in Energetics (IYCE), Proceedings of the 2011 3rd International Youth Conference on, 2011, pp. $1-5$.

[19] A. D. S. Wendlandt, T. Buseth, S. Krauter, P. Grunow, "Hot Spot Risk Analysis on Silicon Cell Modules," in 25th European Photovoltaic Solar Energy Conference and Exhibition / 5th World Conference on Photovoltaic Energy Conversio, Valencia, Spain, 2010, pp. 4002-4006.

[20] H. Haeberlin and M. Real, "Arc Detector for Remote Detection of Dangerous Arcs on the DC Side of PV 
Plants,” in 22nd EU PV Conf., Milano, Italy, 2007.

[21] P. Mastny, L. Radil and Z. Mastna, "Possibilities of PV Panels Defects Identification and Determination of its Effect on the Economy of Photovoltaic Power Plants Op- eration," in Communication and Management in Technological Innovation and Academic Globalization, 2011, pp. 233-238. 